\title{
Monthly Patterns of Testosterone and Behavior in Prospective Fathers
}

\author{
Katharina Hirschenhauser, ${ }^{* 1}$ Didone Frigerio, $\uparrow$ Karl Grammer, $\ddagger$ \\ and Magnus S. Magnusson§ \\ *Instituto Superior de Psicología Aplicada, Unidade de Investigação em Eco-Etología, \\ Lisbon, Portugal; †Konrad Lorenz Forschungsstelle für Ethologie, Grünau, Austria; \\ $\ddagger$ Ludwig Boltzmann Institute for Urban Ethology, Vienna, Austria; and \\ §Human Behavior Laboratory, University of Iceland, Reykjavik, Iceland
}

Received August 10, 2001; revised December 2, 2001; accepted February 12, 2002

The individual time patterns of salivary testosterone of adult healthy men, self-reported sexual behavior and their co-occurrence with regular weekly or monthly intervals were studied. Twenty-seven volunteer males (mean age $33 \pm 1$ years) collected daily morning saliva over a period of $\mathbf{9 0}$ days. Evening questionnaires provided daily information on sexual activity. From the saliva, testosterone immunoreactive substances were determined using enzyme immunoassay. To detect events in which increases of testosterone were associated with sexual activity and at the same time controlling for regular internal patterns in men, data were analyzed using Theme software. First results indicated a varying number of complex nonrandom interaction patterns of testosterone with sexual activity, but also with weekly (i.e., Saturdays) and monthly intervals (i.e., 28-day full-moon intervals). The social context of the occurrence of specific pattern combinations was elaborated using parameters from the men's self-reported general life history profiles. Peak hormone levels occurred around weekends in the majority of the males. The 28-day monthly interval coincided with testosterone peaks only in those of the paired men who reported a current wish for children ("prospective fathers"), but not in unpaired men or in those who did not wish to have children with their current partner. Rather than representing a direct regular pattern of the male testosterone per se, the observed patterns suggest that men have the facultative potential to adjust their testosterone responses to their female partner's cycle. In line with the interactions between behavior and androgens observed in vertebrates in general, this study adds an example of the mutual character

${ }^{1}$ To whom correspondence should be addressed at Unidade de Investigação em Eco-Etologia, ISPA, Rua Jardim do Tabaco 34, 1149-041 Lisbon, Portugal. E-mail: katarina@ispa.pt. of hormone- behavior interactions and, thus, for the social context of testosterone patterns in human males. ๑ 2002 Elsevier Science (USA)

Key Words: testosterone; sexual behavior; hormone behavior interaction; pair bond; human males; real-time patterns; Theme.

Androgens play major roles in the conserved vertebrate reproductive axis (i.e., hypothalamus-pituitarygonads). Testosterone, in particular, is essential for spermatogenesis, the maintenance of the genital tract, and the development of secondary sexual characters in males (Nelson, 2000). Early behavioral endocrinology studies in normal human males were focused predominantly on the interaction between androgens and sexual activity (Brown, Monti, and Corriveau, 1970; Fox, Ismail, Love, Kirkham, and Loraine, 1972). Beard growth rate and concentration were then observed to increase in anticipation of sexual activity (Anonymous, 1970), which along with the development of noninvasive saliva assays (Walker, Wallace, Read, and Riad-Fahmy, 1980; Howard, Kane, Madden, Gosling, and Fottrell, 1989; Dabbs, 1990a; Archer, Birring, and $\mathrm{Wu}, 1998$ ) paved the way to study the role of the social environment and of behavior as short-term modulators of testosterone (Graham and Desjardins, 1980; Hellhammer, Hubert, and Schürmeyer, 1985; Dabbs and Mohammed, 1990; Stoléru, Ennaji, Cournot, and Spira, 1993). In sum, testosterone was observed to influence and, reversibly, be modulated by sexual interest, arousal, and enjoyment, as well as by winning in sports competitions, mood, and physical welfare (Mazur and Lamb, 1980; Hellhammer et al., 1985; Cook, Read, Walker, Harris, and Riad-Fahmy, 
1986; Booth, Shelley, Mazur, Tharp, and Kittok, 1989; Alexander and Sherwin, 1991; Dabbs, 1995; Mazur, Susman, and Edelbrock, 1997; Gonzalez-Bono, Salvador, Serrano, and Ricarte, 1999; Schultheiss, Campbell, and McClelland, 1999). Also on a longer time-scale basal testosterone levels may organize but also interact with life history traits, i.e., with marital status among soldiers (Julian and McKenry, 1989; Booth and Dabbs, 1993) and with violence, aggressiveness, and dominance among prisoners (Kreuz and Rose, 1972; Olweus, Mattson, Schalling and Loew, 1988; Mazur and Booth, 1998). Recently, the testosterone of new fathers was observed to decrease in response to the birth of their infants (Storey, Walsh, Quinton, and Wynne-Edwards, 2000). This was in line with the androgen patterns observed in biparental or paternal fishes, birds, and mammals (Wingfield, Hegner, Dufty, and Ball, 1990; Brown, 1993; Hirschenhauser and Oliveira, 2000; Oliveira, Hirschenhauser, Carneiro, 2002; Wynne-Edwards 2001).

In contrast to the well-known hormonal basis of the menstrual cycle in women (e.g., Van Goozen, Wiegant, Endert, Helmond, and Van de Poll, 1997), a regular internal pattern of hormones and behavior in men, for example, on a monthly basis, to our knowledge has not been studied. The existence of a male "cycle" in terms of hormones and behavior may be considered for a number of reasons. Testosterone plays a role in erectile function, sexual behavior, and mood, which may vary from day to day (Carani, Bancroft, Granata, Del Rio, and Marrama, 1992; Mulligan and Schmitt, 1993; Anderson, Martin, Kung, Everington, Pun, Tan, Bancroft, Sundaram, Moo-Young, and Baird, 1999) or across the days of a week (Palmer, Udry, and Morris, 1982; Wallen, 2001). Furthermore, unconscious autoejaculations during phases of sexual inactivity are common. Finally, physical welfare, concentration, mood, and aggressive as well as sexual motivation may vary noticeably in men (van Niekerk, Huppert, and Herbert, 2001; Zitzmann and Nieschlag, 2001), as observed throughout the female monthly cycle (Schreiner-Engel, Schiavi, Smith, and White, 1981; Kemnitz, Gibber, Lindsay, and Eisele, 1989; Van Goozen et al., 1997). Alternatively, men may be reactive to the hormonal fluctuations and sexual responsivity of their wives (Persky, Lief, Strauss, Miller, and O'Brien, 1978) rather than exhibiting a regular internal cycle themselves (Rowe, Lincoln, Racey, Lehane, Stephenson, Shenton, and Glover, 1974). Observations from a number of species (including the human male) point at the adaptive value for a monogamous male to be hormonally and behaviorally responsive to his partner's fe- cundity phases (Carter, Williams, Witt, and Insel, 1992; Barth, Wallner, Dittami, and Schrams, 1997; Hirschenhauser, Möstl, and Kotrschal, 1999; Storey et al., 2000).

This study was conducted in order to examine regular patterns of testosterone and sexual behavior on a daily basis over a 3-month period in healthy adult men. As a consequence a large database on the interactions between testosterone and sexual activity has been acquired. Peak levels of testosterone were expected in response to sexual activity (Alexander and Sherwin, 1991; Zitzmann and Nieschlag, 2001). Analyses focused on three major questions: (a) whether the males' testosterone peaks anticipated or followed periods of sexual activity, (b) the social context of the observed interaction patterns, and (c) a potential involvement of regular environmental parameters in the observed time patterns. The involvement of regular environmental parameters in the observed time patterns included weekly and monthly intervals. The rates of co-occurrences between testosterone peaks and sexual activity were compared with regard to social context and life histories of the candidates. To test the effect of the family status, the observed patterns were compared between paired and unpaired men, as well as between fathers and nonfathers. To distinguish the effects of being paired from the effects specifically related to reproduction, we asked whether the observed interaction patterns between testosterone and sexual activity were modulated by the males' current commitment to reproduction ("prospective fathers"). This study is the first to examine prospective fathers, i.e., the males' commitment to reproduction as a variable for the interaction between testosterone and sexual activity.

\section{MATERIALS AND METHODS}

Twenty-seven adult, anonymous, volunteer males collected daily morning saliva samples for a period of 90 days using salivette devices (Sarstedt). Each candidate was provided with a sampling package, which included 90 salivettes labeled for each day, 90 "daily questionnaires" to be completed every evening, and a singular "general questionnaire" to be filled in once at the beginning of the sampling period. At distribution of the sampling packages, the candidates randomly drew a number code and were thereafter treated anonymously by use of the number codes.

The mode of saliva collection was introduced to the males. To standardize variation due to time of day 
(Nieschlag and Ismail, 1970; Rowe et al., 1974) and to avoid contamination of the samples by food or toothpaste, saliva was collected every morning right after waking up. Candidates stored the samples at their houses at $-20^{\circ} \mathrm{C}$ until further processing. All of them started their sampling periods between May and June 1998 to minimize the potential effects of season on testosterone patterns (Dabbs, 1990b). Mean age of the candidates was $33 \pm 1$ years (ranging from 23 to 47 years). This study included men from various professions and from different environments, 18 candidates lived in urban settings (Vienna, Austria, and Bergamo, Italy), and 8 lived in a rural environment (Austria).

\section{Testosterone Assays}

Immunoreactive testosterone equivalents were assayed from a total of 2190 saliva samples by enzyme immunoassay (EIA) using a group-specific antibody against 4-androstene-17 $\beta$-ol-3-on-carboxymethyloxine: albumin (rabbit). As label $5 \alpha$-androstane- $3 \beta, 17 \beta$-diol3-hemisuccinate (Palme and Möstl, 1993) was used for biotinylation (diaminodioxaoctane-biotin). Assay concentration limits for reliable measurement ranged from 80 to $20 \%$ binding, which corresponded to a range of 26.7 to $939.9 \mathrm{pg}$ testosterone per milliliter of saliva. The specificity of the testosterone EIA was determined by HPLC (Palme, Möstl, Schellander, and Bamberg, 1997) and resulted in a dominating peak with the same elution pattern as testosterone.

All samples were stored at $-20^{\circ} \mathrm{C}$, and treatment periods outside the freezer were always kept to a minimum. After centrifugation at $19.125 \mathrm{~g}$ for $10 \mathrm{~min}$ at $20^{\circ} \mathrm{C}$, approximately $2 \mathrm{ml}$ of the fluid compound of the saliva was recovered from the salivettes. Wherever any saliva was present in surplus it was collected for a joint homogenized pool sample. The samples were singularly entered into the EIA at a dilution of $30 \mu \mathrm{l}$ saliva to $20 \mu \mathrm{l}$ assay buffer without prior diethyl-ether extraction (Howard et al., 1989; Schultheiss et al., 1999; own unpublished data). A total of 40 assays were run, and individual samples were always distributed over 2 assays. Repeated measurements of duplicate pool samples at the first 2 and the last 2 cups of each microtiter plate revealed a mean inter-assay coefficient of variation of $12.4 \%$ per individual; the mean intraassay coefficient of variation was $8.2 \%$.

\section{Behavioral Parameters}

Self-reports of each day's eventual sexual activities (including masturbation) were recorded using a daily questionnaire to be completed every evening. Furthermore, the candidates were asked whether sexual activity occurred with a familiar partner and had to indicate the intensity of the sexual activity by intuitively placing a mark along a scale of $50 \mathrm{~mm}$, where " 0 " represented low intensity and " 50 " indicated very intensive sexual activity. As environmental parameters, weekends and full-moon intervals were coded post hoc by the authors. Daily behavioral events as well as the environmental parameters were then analyzed for their interaction/co-occurrence with testosterone peaks.

A singular general questionnaire was collected in order to assess information on the males' life history traits, such as being paired, the pair-bond duration, whether they were fathers already, whether they had the wish to have children with their current partner (prospective fathers) or "not with this partner." The life history traits were used as social categories for the elaboration of the social context of the occurrence of nonrandom testosterone-behavior patterns.

\section{Theme Patterns}

For statistical processing, days with peak occurrences were determined from all hormonal and behavioral variables, and thereby between-male variation of amplitudes was not a subject of the subsequent analyses. Peaks were chosen rather than troughs as the focus of this study was on testosterone increases in response to sexual activity, as well as on the reverse direction of these interactions (Stoléru et al., 1993). A "peak" was defined as an androgen level greater than or equal to the individual mean plus standard deviation (Edwards, Reburn, and Wynne-Edwards, 1995; Fig. 1) and as sexual activities of intensities greater than 35 (data above the third quartile). To detect events in which a testosterone peak was associated with sexual activity and at the same time controlling for regular internal patterns in men, data were further processed by the use of Theme (Magnusson, 1996; 2000), which is a software program specifically designed for the detection and analysis of repeated nonrandom behavioral patterns hidden within complex real-time behavior records. Each time pattern is essentially a repeated chain of some particular set of behavioral event types (A B C D . . .) characterized by fixed event order (and/or co-occurrence) and time distances $(\geq 0)$ between the consecutive parts of the chain that are significantly similar in all occurrences of the chain (Magnusson, 1996; 2000). In this context, an important aspect of this pattern type is that its definition does not 
rely on cyclical organization; i.e., the full pattern and/or its components may or may not occur in a cyclical fashion. In order to perform Theme analyses on the repeated measurements of each individual the number of actors was 1 in this study. A minimum of three repeated pattern occurrences throughout the 90day sampling period and a 0.05 significance level were specified. Theme identified time periods when testosterone peaks and sexual activity co-occurred (i.e., in Fig. 1 when levels are outside of the shaded area and when a circle is indicated above the peak). The detection of a nonrandom time pattern may, thus, be regarded as a measure of the interaction between testosterone and sexual behavior or of the co-occurrence with an environmental parameter. From the numerous detected nonrandom time patterns per individual the "frequency of occurrence" ( $N$ occurrences divided by the total duration of the sampling period) of each male's most complex pattern within the 90 days was derived. The frequency of occurrence was compared between those 22 candidates in whom Theme detected patterns involving both testosterone and behavioral variables.

\section{Social Context of the Observed Interactions and Environmental Parameters}

Furthermore, the proportion (\%) of all time patterns that involved a significant interaction between testosterone and sexual activity was determined per individual. In order to elaborate a possible prevalent direction of the interaction, time patterns ranking the testosterone peak before the behavior were distinguished from time patterns that ranked the behavioral event before the testosterone peak. To compare observed time patterns that involved regular environmental parameters, the number of detected time patterns that involved weekly intervals (i.e., Saturdays) and monthly intervals (i.e., the 28-day intervals between full-moons) was determined per individual and compared between social (life history) categories.

The number of individuals may vary among the different analyses because the daily questionnaires of 5 candidates were not returned and thus missing, one candidate did not return his general life history questionnaire, and for another male information on children was not provided. Therefore, time patterns involving testosterone and behavior were available from 22 males, comparisons between different social categories could be performed among 21 males, and comparisons between children-related parameters could be performed among 20 males. Phenology and analy-

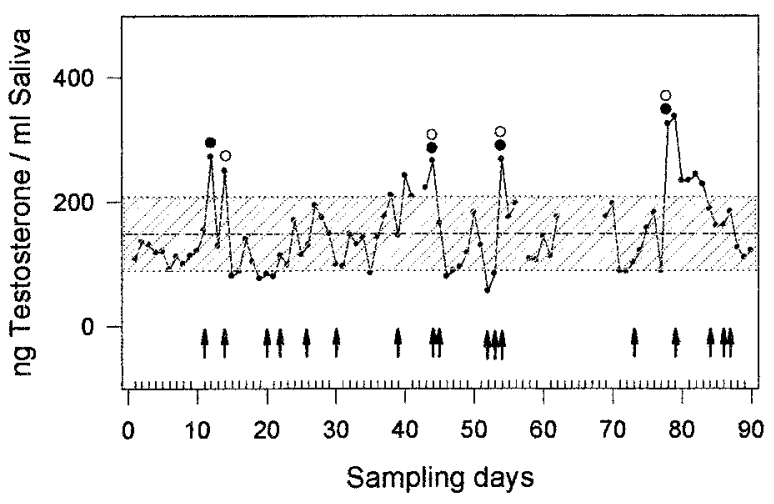

FIG. 1. Example of an individual testosterone pattern over the 90-day sampling period. Shaded area represents the individual mean \pm standard deviation. Arrows indicate days with reported sexual activity of intensity greater than 35 . Circles above peaks (i.e., testosterone levels greater than mean + standard deviation) indicate days on which Theme (Magnusson, 1996; 2000) detected testosterone peaks following sexual behavior (filled circles) or sexual activity following a peak in morning testosterone levels (open circles).

ses of time patterns involving "environmental parameters," such as weekly or monthly intervals, were independent of the number of returned daily questionnaires and, therefore, available from 27 males (comparisons between social categories: 26 males; comparisons related to children: 25 males). To control for the effects of season, sampling time, age (Dabbs, 1990a,b), and pair-bond duration, Spearman's rank correlations were employed. Temporal sequences of the observed interactions between testosterone and behavior were compared using Wilcoxon tests matched for individuals. The comparisons between social categories were performed using nonparametric statistics (Mann-Whitney $U$ test). All probabilities are given two-tailed.

\section{RESULTS}

\section{Phenology of Testosterone Patterns}

Twenty-seven men delivered on average 86 of the 90 requested daily morning saliva samples (with a range between 54 and 90). Amplitudes of the observed individual testosterone fluctuations varied to a great extent over the sampling period (mean maxima \pm $\mathrm{SEM}=1100 \pm 100 \mathrm{ng} / \mathrm{ml}$ with a range between 200 and $1313 \mathrm{ng} / \mathrm{ml}$; mean coefficient of variation \pm SEM $=49.3 \pm 3.4 \%, N=27$; Fig. 1 ). However, the testosterone variation observed in this data set was not due 


\section{TABLE 1}

Variables with Potential Confounding Effects on the Observed Variation in Testosterone among the Studied Sample of Adult Healthy Men

\begin{tabular}{|c|c|c|c|c|}
\hline & Season $(N=27)$ & Sampling time $(N=26)$ & Age $(N=26)$ & Pair-bond duration $(N=25)$ \\
\hline Mean testosterone level & $\begin{aligned} r_{s} & =0.21 \\
P & =0.284\end{aligned}$ & $\begin{aligned} r_{s} & =-0.03 \\
P & =0.878\end{aligned}$ & $\begin{aligned} r_{s} & =0.30 \\
P & =0.133\end{aligned}$ & $\begin{aligned} r_{s} & =0.02 \\
P & =0.919\end{aligned}$ \\
\hline Maximum amplitude & $\begin{array}{l}r_{s}=0.05 \\
P=0.807\end{array}$ & $\begin{aligned} r_{s} & =-0.02 \\
P & =0.915\end{aligned}$ & $\begin{aligned} r_{s} & =0.33 \\
P & =0.104\end{aligned}$ & $\begin{aligned} r_{s} & =0.02 \\
P & =0.931\end{aligned}$ \\
\hline Coefficient of variation & $\begin{aligned} r_{s} & =-0.15 \\
P & =0.461\end{aligned}$ & $\begin{aligned} r_{s} & =-0.16 \\
P & =0.436\end{aligned}$ & $\begin{aligned} r_{s} & =-0.03 \\
P & =0.868\end{aligned}$ & $\begin{aligned} r_{s} & =0.02 \\
P & =0.933\end{aligned}$ \\
\hline
\end{tabular}

Note. Table shows Spearman's rank correlation coefficients $\left(r_{s}\right)$ of individual mean testosterone levels over the 90-day sampling period, individual maximum amplitudes and individual coefficients of variation over the total sampling period with season (date of the first sample), sampling time (time of the day), age, and pair-bond duration. See text for details of varying sample sizes.

to effects of season, sampling time, age, or pair-bond duration (Table 1). On average, the candidates woke up and delivered their samples at rather regular times of the day $(7: 59 \pm 0: 10 \mathrm{~h} ; N=26)$, even though there was a tendency for later wake-up times around weekends as compared to weekdays. Thus, although not ideal, these data reflect daily patterns of morning testosterone levels in 27 healthy men monitored over a 3-month period.

In general, an overall interaction of testosterone with parameters in a direct sexual context was observed. For example, in the seven men who reported sexual activity with an unfamiliar partner, salivary testosterone of the next morning was on average up to $100 \%$ (ranging from 60 to $330 \%$ ) higher than their individual average levels. Moreover, testosterone amplitudes of the six candidates who reported sexual activities with more than one partner within the preceding $24 \mathrm{~h}$ were on average $140 \%$ (ranging from 60 to $456 \%$ ) higher than their individual average testosterone levels.

\section{Time Patterns}

Theme detected a total of 1641 nonrandom timepattern combinations that involved testosterone (mean diversity $\pm \mathrm{SEM}=75 \pm 16$ per individual, $N=$ 22). These time patterns were composed of variably complex event combinations that occurred with different frequencies throughout the sampling period among candidates. In the majority of candidates (19 of 22 males) the most complex patterns occurred with a frequency of 0.03 , i.e., three times throughout the 90 days.

\section{Social Context of the Observed Interactions}

An interaction between testosterone and sexual activity was detected in $75 \%$ of all time patterns that involved testosterone (total number $=1238$; mean \pm $\mathrm{SEM}=59 \pm 13$ per individual; $N=22$ ). The proportions of time patterns that involved testosterone and sexual activity were not different between unpaired and paired men $(Z=-1.08 ; N=5 / 16 ; P=0.28$; Fig. 2A) and also not different between nonfathers and fathers $(Z=-1.52 ; N=16 / 4 ; P=0.13$; Fig. $2 B)$. However, the specific interactions between testosterone and sexual activity were more frequent among prospective fathers than among men who had no partner or did not want to have children with their current partner $(Z=-2.13 ; N=7 / 9 ; P=0.031$; Fig. $2 B)$.

To elucidate the temporal sequence of the observed interactions, the proportion of all observed time patterns that involved the morning testosterone peak preceding a behavioral event during the day was compared with the proportion of time patterns that involved the behavior reported from 1 day preceding a testosterone peak on the next morning (for an example see Fig. 1) in all candidates (Fig. 2C). No significant difference of interactions between sexual activity and testosterone in either direction (Wilcoxon: $Z=$ $-1.023 ; N=22 ; P=0.31$ ) was found. Therefore, the presented time patterns were not to be regarded as interactions with one prevalent direction, but probably rather represented a high degree of a two-way type of interaction between sexual behavior and testosterone levels in all males sampled.

\section{Environmental Modulation of Time Patterns}

Time patterns involving testosterone and weekly intervals (i.e., Saturdays) were observed in 24 of the 27 males. Theme, furthermore, detected a large number of time patterns involving testosterone and monthly intervals (i.e., the 28 -day period of full-moon phases) in 15 of 27 males. Because this interval echoes the average length of the female cycle, we expected to find 

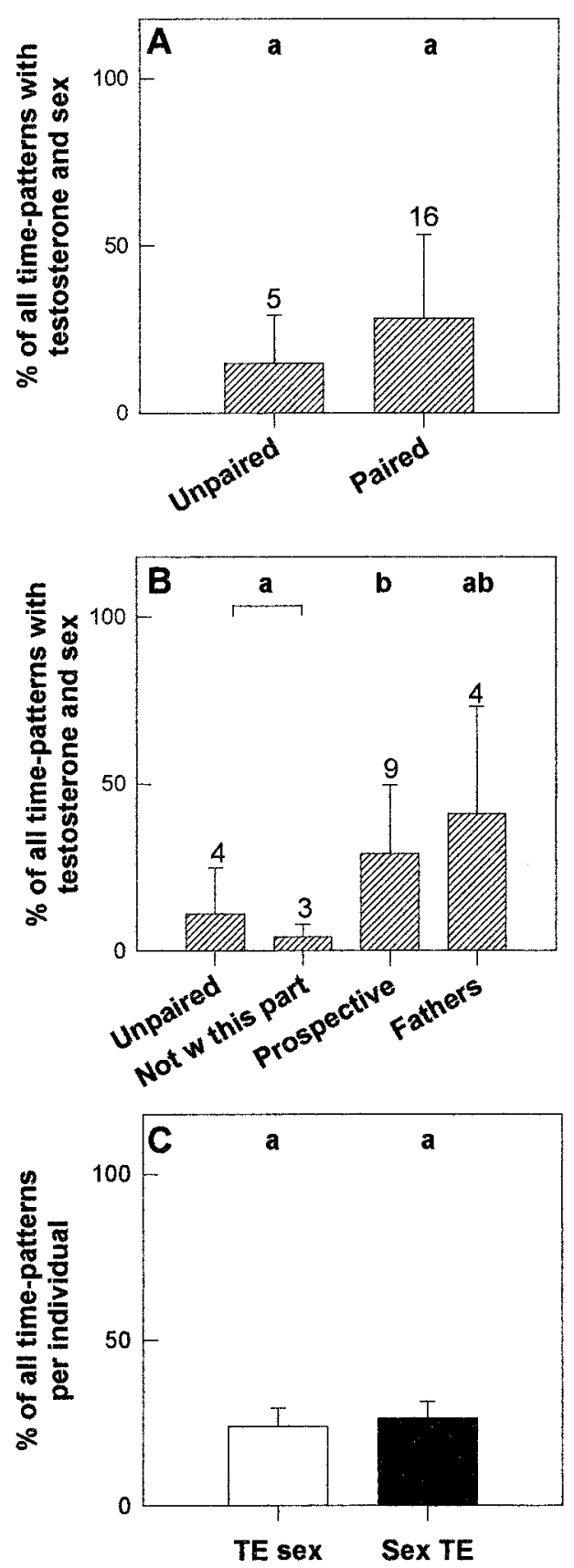

FIG. 2. (A) Proportion of time patterns that involved testosterone and sexual activity (in either sequence) occurred at non significantly different rates in unpaired and paired men. (B) "Prospective fathers" showed a larger proportion of time patterns that involved an interaction between sexual activity and testosterone (in either sequence) than unpaired men or those who did not wish to have children with their current partner. (C) There was no difference $(N=21$; matched pairs) between the proportion of all detected time patterns per individual that involved sexual activity preceding a peak of testosterone (TEsex, open bars) and the proportion of time patterns that detected sexual activity following a peak morning testosterone level (SexTE, black bars). Bars represent mean this interaction in paired rather than in unpaired men. Surprisingly, the observed variation of male monthly time patterns could not be explained by being paired or not $(Z=-1.20 ; N=6 / 20 ; P=0.23$; Fig. $3 \mathrm{~A})$. However, as already observed for the interaction with sexual activity, the testosterone peaks interacting with monthly intervals also occurred significantly more frequent in prospective fathers as compared to those men who had no partner or did not want to have children with their current partner $(Z=-2.22 ; N=$ $9 / 10 ; P=0.026$; Fig. 3B). There was no difference in the occurrences of monthly testosterone patterns of nonfathers or fathers $(Z=-0.10 ; N=19 / 6 ; P=$ 0.92; Fig. 3B).

\section{DISCUSSION}

The effect of the social context on androgen fluctuations is not a new concept in nonhuman behavioral endocrinology (Wingfield et al., 1990; Oliveira, 1998; Hirschenhauser and Oliveira, 2000; Wallen, 2001). However, studies on the social modulation of testosterone response patterns in human males suffer from the complexity of social interactions and from the ethical restriction of designing controlled studies in our own species. Here, the application of Theme analyses (Magnusson, 1996, 2000) resulted in time patterns that may be regarded as measures of the co-occurrence of testosterone with sexual behavior. Such time patterns also provide information on the temporal sequence of the parameters involved. Dabbs and Mohammed (1990) found that sexual activity affected testosterone more than initial testosterone affected sexual activity, where saliva samples had been collected immediately before and after sexual activity. In this study, on a daily morning basis, no prevalent direction of the relationship between testosterone peaks and sexual behavior was detected (Fig. 2C); rather there seems to have been a high degree of mutual interaction.

The existence of a regular cycle of hormones and sexual behavior in human males has been an open question so far and the results of this study did not provide direct support for this hypothesis. The known

percentage \pm standard error, different letters above bars represent significant differences between social categories $(P<0.05)$, and numbers inside or above bars are the numbers of individuals per category. 

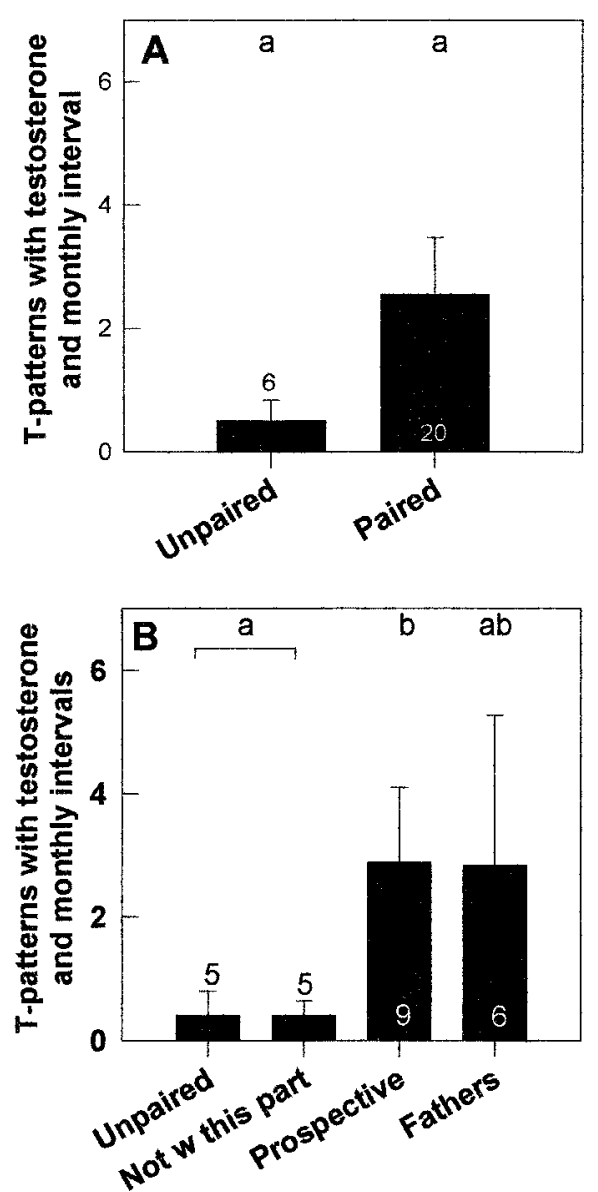

FIG. 3. The number of detected time patterns that involved testosterone at monthly intervals (i.e., the 28-day intervals of fullmoons) per individual. (A) The difference between unpaired and paired men was not significant. (B) In "prospective fathers" Theme detected more time patterns that involved testosterone at monthly intervals than in unpaired men or those who did not want to have children with their current partner. Bars represent means \pm standard error, different letters above bars represent significant differences between social categories $(P<0.05)$, and numbers inside or above bars are the numbers of individuals per category.

peak of sexual intercourse in couples around weekends (Palmer et al., 1982) was reflected in the currently observed co-occurrences of sexual activity and testosterone with weekends. This does not point at a male cycle in any parameter, but rather at the males' hormonal responsiveness to sexual activities. With regard to a potential male responsiveness to the 28-day interval of the female's menstrual cycle, one would expect to observe such response patterns in paired men rather than in singletons. Our results, however, did not confirm this prediction. The occurrences of observed time patterns that involved testosterone at monthly intervals differed due to the reproductive context of the males' relationship to a regular partner, rather than to being paired per se. In specific, the wish to have children with a current partner explained both the observed degree of interaction between testosterone and sexual activity and the occurrence of monthly intervals in the males' testosterone fluctuations. Thus, men who had revealed a reproductive context to the sexual activities with their partners showed different testosterone response patterns than men who reported sexual activities without commitment to reproduction. As $75 \%$ of all time patterns involved an interaction between testosterone and sexual activity, one may argue that these similarly emerging pictures are to be regarded as simple artifacts of a higher diversity of time patterns in general. However, there was no similar result observed with time patterns that involved testosterone and weekly intervals or with the frequency of occurrence. Furthermore, an effect of using oral contraceptives, which affects the regularity of the female's 28-day period, may be excluded from this study, because its use was reported in only two cases. We also controlled for a possible effect of sharing the household with a partner, but there was no difference in any of the parameters between paired men living in shared households versus paired men living in single households (time patterns involving sex and testosterone: $Z=-0.54 ; N=10 / 6 ; P=0.59$; time patterns involving testosterone at monthly intervals: $Z=$ $-0.28 ; N=11 / 9 ; P=0.78)$. Therefore, the observed patterns between testosterone and sex and the monthly interval of these interactions in prospective fathers may point at the males' facultative hormonal and behavioral responsiveness to their female partner's cycle. We suggest that our results reflected the indirect responses of prospective fathers to their female partners' regular monthly cycles, rather than internal male rhythms. Because these monthly patterns were not observed in all paired males, the males' testosterone responsiveness to their partners seemed to be specifically related to reproduction.

The concept that males may potentially respond and adapt to their partners' hormonal and fecundity phases has been proposed before. In small mammals, rapid, but long-lasting oxytocin increases were found in both partners during pair formation (Carter et al., 1992; Barth et al., 1997). In a socially monogamous bird the within-pair testosterone co-variation between the male and the female partner's seasonal levels reflected the pair's reproductive success (Hirschenhauser et al., 1999). Human males' testosterone was shown to correspond to the partner's sexual responsivity scores (Persky et al., 1978). Recently, Storey et al. (2000) re- 
ported that testosterone of expectant fathers was specifically related to the women's hormone levels, rather than to the time before birth. Taken together, these phenomenona are based on mechanisms associated with social monogamy, including affiliation, paternal care, and pair bonding. The males' wish for children with a specific partner, which led to the distinction of prospective fathers in this study, may be regarded as one possible approach to express the intensity and the subjective perception of a pair bond in human males. One might even speculate that prospective fathers had to invest in mate-guarding more intensively and therefore, were responding more specifically to their partners' behavior than, for example, men who had a sexual partner but were not willing to invest in parental care with this partner. This "mate-guarding hypothesis" among human males remains one exciting field for future research.

Finally, the androgen response patterns of fathers were compared with those of nonfathers. Based on the literature from nonhuman vertebrates (Wingfield et al., 1990; Brown, Murdoch, Murphy, and Moger, 1995; Wynne-Edwards and Reburn, 2000; Wynne-Edwards, 2001), larger rates of androgen responsiveness to sexual "challenges" would be expected in fathers than in men without paternal duties. The patterns measured from fathers in this study appeared to be intermediate between frequent occurrences in prospective fathers and very rare occurrences in unpaired men or those who did not want to have children. In addition to the small sample size, variation among fathers was large (Figs. 2B and 3B). Measurements of additional fathers may have resulted in a clearer picture. The degree of paternal investment, however, was not optimally covered in the present study. The classification "fathers", for example, did not necessarily explain any degree of paternal duties or emotional involvement (Elwood and Mason, 1994; Storey et al., 2000). Furthermore, fathers did not explicitly report their wish to have more children or no more children, which probably also confounded clearer patterns in this category. Research on the behavioral endocrinology of human fatherhood remains of current interest (Wynne-Edwards, 2001) and in the future may even benefit from the use of Theme analyses to express "real-time response patterns."

Similar to most studies in human behavioral endocrinology, the present analyses should be seen as what they are: restrictive, but valuable (Zitzmann and Nieschlag, 2001). Although descriptive, this study may have raised a number of functional hypotheses that certainly demand improved statistical power and controlled evaluation in the future. Specifically, we propose that men have the facultative potential to hormonally and behaviorally respond to their partner's cycle. Most importantly, this study has examined the effect of the commitment to reproduction when studying interactions between male testosterone and sexual activity. However, the speculation that men who have no wish to have a family with their current partner might remain hormonally and psychologically unresponsive to their partner's fertility phase seems not trustworthy. In general, the need to consider the complex influence of the psychoendocrinological and social context of human males' testosterone responsivity to behavioral and physical environment was pinpointed.

\section{ACKNOWLEDGMENTS}

Our special acknowledgment goes to the 27 volunteers who provided the saliva samples and behavioral data. The KLF Grünau, two anonymous sponsors, and the Vienna local board (H.C. Ehald) provided financial support. We acknowledge the technical expertise of E. Möstl, A. Kuchar-Schulz, H. Spendier, and M. Stark from the Institute for Biochemistry at the Veterinary University of Vienna and thank them for the lab space. Furthermore, we thank L. A. Carneiro, N. J. Cook, H. Fuchs, A. Hirschenhauser, A. Jütte, K. Kotrschal, R. F. Oliveira, M. Ortobelli, A. Ros, F. Schachinger, and B. Valoti for their assistance. K. Wynne-Edwards and two anonymous referees provided very helpful comments on an earlier draft of the manuscript. K.H. was supported by a postdoctoral grant from the Fundação para a Sciência e a Tecnologia (FCT: PRAXIS XXI/BPD/ 20142/99).

\section{REFERENCES}

Alexander, G. M., and Sherwin, B. B. (1991). The association between testosterone, sexual arousal, and selective attention for erotic stimuli in men. Horm. Behav. 25, 367-381.

Anderson, R. A., Martin, C. W., Kung, A. W., Everington, D., Pun, T. C., Tan, K. C., Bancroft, J., Sundaram, K., Moo-Young, A. J., and Baird, D. T. (1999). $7 \alpha$-methyl-19-nortestosterone maintains sexual behavior and mood in hypogonadal men. J. Clin. Endocrinol. Metab. 84, 3556-3562.

Anonymous (1970). Effects of sexual activity on beard growth in man. Nature 226, 869-870.

Archer, J., Birring, S. S., and Wu, F. C. W. (1998). The association between testosterone and aggression among young men: Empirical findings and a meta-analysis. Aggr. Behav. 24, 411-420.

Barth, R., Wallner, B., Dittami, J., and Schrams, D. (1997). Oxytocin as a means or end to pair bonding: Data from guinea pigs. $A d v$. Ethol. 32, 58.

Booth, A., and Dabbs, J., Jr. (1993). Testosterone and men's marriages. Soc. Forces 72, 463-477.

Booth, A., Shelley, G., Mazur, A., Tharp, G., and Kittok, R. (1989). 
Testosterone, and winning and losing in human competition. Horm. Behav. 23, 556-571.

Brown, R. E. (1993). Hormonal and experimental factors influencing parental behaviour in male rodents: An integrative approach. Behav. Proc. 30, 1-28.

Brown, R. E., Murdoch, T., Murphy, P. R., and Moger, W. H. (1995). Hormonal responses of male gerbils to stimuli from their mate and pups. Horm. Behav. 29, 474-491.

Brown, W. A., Monti, P. M., and Corriveau, D. P. (1970). Serum testosterone and sexual activity and interest in men. Arch. Sex. Behav. 7, 97-103.

Carani, C., Bancroft, J., Granata, A., Del Rio, G., and Marrama, P. (1992). Testosterone and erectile function, nocturnal penile tumescence and rigidity, and erectile response to visual erotic stimuli in hypogonadal and eugonadal men. Psychoneuroendocrinology 17, 647-654.

Carter, C. S., Williams, J. R., Witt, D. M., and Insel, T. R. (1992). Oxytocin and social bonding. Ann. N.Y. Acad. Sci. 12, 204-211.

Cook, N., Read, G. F., Walker, R. F., Harris, B., and Riad-Fahmy, D. (1986). Changes in adrenal and testicular activity monitored by salivary sampling in males throughout marathon runs. Eur. J. Appl. Physiol. 55, 634-638.

Dabbs, J. M. Jr. (1990a). Salivary testosterone measurements: Reliability across hours, days, and weeks. Physiol. Behav. 48, 83-86.

Dabbs, J. M. Jr. (1990b). Age and seasonal variation in serum testosterone concentration among men. Chronobiol. Int. 7, 245-249.

Dabbs, J. M. Jr. (1995). Winning with testosterone. Science 269, 1341-1343.

Dabbs, J. M. Jr., and Mohammed, S. (1990). Male and female salivary testosterone concentrations before and after sexual activity. Physiol. Behav. 52, 195-197.

Edwards, H. E., Reburn, C. J., and Wynne-Edwards, K. E. (1995). Daily patterns of pituitary prolactin secretion and their role in regulating maternal serum progesterone concentrations across pregnancy in the Djungarian hamster (Phodopus campbelli). Biol. Reprod. 52, 814-823.

Elwood, R. W., and Mason, C. (1994). The couvades and the onset of paternal care: A biological perspective. Ethol. Sociobiol. 15, 145156.

Fox, C. A., Ismail, A. A. A., Love, D. N., Kirkham, K. E., and Loraine, J. A. (1972). Studies on the relationship between plasma testosterone levels and human sexual activity. J. Endocr. 52, 51-58.

Gonzalez-Bono, E., Salvador, A., Serrano, M. A., and Ricarte, J. (1999). Testosterone, cortisol, and mood in a sports team competition. Horm. Behav. 35, 55-62.

Graham, J. M., and Desjardins, C. (1980). Classical conditioning: Induction of $\mathrm{LH}$ and testosterone secretion in anticipation of sexual activity. Science 210, 1039-1041.

Hellhammer, D. H., Hubert, W., and Schürmeyer, T. (1985). Changes in saliva testosterone after psychological stimulation in men. Psychoneuroendocrinology 10, 77-81.

Hirschenhauser, K., Möstl, E., and Kotrschal, K. (1999). Within-pair testosterone co-variation and reproductive output in Greylag geese (Anser anser). Ibis 141, 577-586.

Hirschenhauser, K., and Oliveira, R. F. (2000). The challenge hypothesis revisited: A meta-analysis. Trabajos Inst. Cajal 77, 305.

Howard, K., Kane, M., Madden, A., Gosling, J. P., and Fottrell, P. F. (1989). Direct solid-phase enzyme immunoassay of testosterone in saliva. Clin. Chem. 35, 2044-2047.

Julian, T., and McKenry, P. C. (1989). Relationship of testosterone to men's family functioning at mid-life: A research note. Aggr. Behav. 15, 281-289.
Kemnitz, J. W., Gibber, J. R., Lindsay, K. A., and Eisele, S. G. (1989). Effects of ovarian hormones on eating behaviors, body weight, and glucoregulation in rhesus monkeys. Horm. Behav. 23, 235-250.

Kreuz, L. E., and Rose, R. M. (1972). Assessment of aggressive behavior and plasma testosterone in a young criminal population. Psychosom. Med. 34, 321-332.

Magnusson, M. S. (1996). Hidden real-time patterns in intra- and inter-individual behavior: Description and detection. Eur. J. Psychol. Assessment 12, 112-123.

Magnusson, M. S. (2000). Discovering hidden time patterns in behavior: T-patterns and their detection. Behav. Res. Meth. Instr. Comp. 32, 93-110.

Mazur, A., and Booth, A. (1998). Testosterone and dominance in men. Behav. Brain Sci. 21, 353-397.

Mazur, A., and Lamb, T. (1980). Testosterone, status, and mood in human males. Horm. Behav. 14, 236-246.

Mazur, A., Susman, E. J., and Edelbrock, S. (1997). Sex difference in testosterone response to a video game contest. Evol. Human Behav. 18, 317-326.

Mulligan, T., and Schmitt, B. (1993). Testosterone for erectile failure. J. Gen. Int. Med. 8, 517-521.

Nelson, R. (2000). An Introduction to Behavioral Endocrinology, 2nd ed. Sinauer, Sunderland, MA.

Nieschlag, E., and Ismail, A. A. (1970). Diurnal variations of plasma testosterone in normal and pathological conditions as measured by the technique of competitive protein binding. J. Endocr. 46, 3-4.

Oliveria, R. F. (1998). Of fish and men: A comparative approach to androgens and social dominance. Behav. Brain Sci. 21, 383-384.

Oliveria, R. F., Hirschenhauser, K., Carneiro, L. A., and Canario, A. V. M. Social modulation of androgens in male teleost fish. Comp. Biochem. Physiol. C132, 203-215.

Olweus, D., A. Mattson, Schalling, D., and Loew, H. (1988). Circulating testosterone levels and aggression in adolescent males: A causal analysis. Psychosomat. Med. 50, 261-272.

Palme, R., and Möstl, E. (1993). Biotin-streptavidin enzyme immunoassay for the determination of oestrogens and androgens in boar feces. In S. Görög (Ed.), Advances of Steroid Analysis '93, pp. 111-117. Akadémia: Kiadó, Budapest.

Palme, R., Möstl, E., Schellander, K., and Bamberg, E. (1997). Faecal metabolites of infused ${ }^{14} \mathrm{C}$-progesterone in domestic livestock, Reprod. Dom. Anim. 32, 199-206.

Palmer, J. D., Udry, J. R., and Morris, N. M. (1982). Diurnal and weekly, but no lunar rhythms in human copulation. Arch. Sex. Behav. 7, 157-173.

Persky, H., Lief, H. I., Strauss, D., Miller, W. R., and O'Brien, C. P. (1978). Plasma testosterone level and sexual behavior of couples. Arch. Sex. Behav. 7, 157-173.

Rowe, P. H., Lincoln, G. A., Racey, P. A., Lehane, J., Stephenson, M. J., Shenton, J. C., and Glover, T. D. (1974). Temporal variations of testosterone levels in the peripheral blood plasma of men. $J$. Endocr. 61, 63-73.

Schreiner-Engel, P., Schiavi, R. C., Smith, H., and White, D. (1981). Sexual arousability and the menstrual cycle. Psychosom. Med. 43, 199-214.

Schultheiss, O., Campbell, K. L., and McClelland, D. C. (1999). Implicit power motivation moderates men's testosterone responses to imagined and real dominance. Horm. Behav. 36, 234241.

Stoléru, G. S., Ennaji, A., Cournot, A., and Spira, A. (1993). LH pulsatile secretion and testosterone blood levels are influenced by sexual arousal in human males. Psychoneuroendocrinology 18, 205218. 
Storey, A. E., Walsh, C. J., Quinton, R. L., and Wynne-Edwards, K. E. (2000). Hormonal correlates of paternal responsiveness in new and expectant fathers. Evol. Human Behav. 21, 79-95.

Van Goozen, S. H., Wiegant, V. M., Endert, E., Helmond, F. A., and Van de Poll, N. E. (1997). Psychoendocrinological assessment of the menstrual cycle: The relationship between hormones, sexuality, and mood. Arch. Sex. Behav. 26, 359-382.

van Niekerk, J. K., Huppert, F. A., and Herbert, J. (2001). Salivary cortisol and DHEA: Association with measures of cognition and well-being in normal older men, and effects of three months of DHEA supplementation. Psychoneuroendocrinology 26, 591-612.

Walker, R. F., Wallace, D. W., Read, G. F., and Riad-Fahmy, D. (1980). Assessment of testicular function by radioimmunoassay of testosterone in saliva. Int. J. Androl. 3, 105-120.
Wallen, K. (2001). Sex and context: Hormones and primate sexual motivation. Horm. Behav. 40, 339-357.

Wingfield, J. C., Hegner, R. M., Dufty, A. M., Jr., and Ball, G. F. (1990). The 'challenge hypothesis': Theoretical implications for patterns of testosterone secretion, mating systems, and breeding strategies. Am. Nat. 136, 829-846.

Wynne-Edwards, K. E. (2001). Hormonal changes in mammalian fathers. Horm. Behav. 40, 139-145.

Wynne-Edwards, K. E., and Reburn, C. J. (2000). Behavioral endocrinology of mammalian fatherhood. TREE 15, 464-468.

Zitzmann, M., and Nieschlag, E. (2001). Testosterone levels in healthy men and the relation to behavioural and physical characteristics: Facts and constructs. Eur. J. Endocrinol. 144, 183197. 